\title{
THE RELATIONSHIP BETWEEN THE EXISTENCE AND DEGREE OF CORONARY ARTERY DISEASE WITH THE LEVEL OF PARATHORMONE
}

İ̇smail Beypınar, ${ }^{2}$ Ramazan Can Öncel, ${ }^{3}$ Sebahat Özdem, ${ }^{4}$ Ramazan Sarı, ${ }^{4}$ Mustafa Kemal Balcı, ${ }^{4}$ Hasan Altunbaş

${ }^{1}$ Akdeniz University Medicine Faculty Department of Internal Medicine , ${ }^{2}$ Cardiology, ${ }^{3}$ Biochemistry,

${ }^{4}$ Endocrinology and Metabolism

\section{AIM}

Parathormone $(\mathrm{PTH})$ is one of the major regulator of the bone and mineral

metabolism.

Elevated PTH levels in patients with primary and secondary hyperparathyroidism is thought to have negative effects on the cardiovascular system.

In our study, we aimed to investigate a possible relationship between plasma PTH levels and coronary atherosclerosis.

\section{METHODS}

Fourty two men and 35 women, a total of 77 patients were included the study who admitted cardiology clinic because of chest pain.

The patients had no previously known coronary artery disease. The patients who use a drug or have a disease which can affect calcium or PTH levels were excluded.

Plasma lipids, calcium, phosporus, albumin, intact PTH and $25-\mathrm{OH}$ vitamin D levels were measured from the blood samples which were taken one hour before the angiography procedure following a 8 hours fasting

The existence and degree of coronary atherosclerosis were evaluated with Gensini Score from images of angiograms.

SPSS 13.0 was used for statistical analyze.

\section{RESULTS}

When the all risk factors are evaluated we found no relationship between the existence and degree of coronary atherosclerosis and levels of PTH and 25-OH vitamin D levels.

Also when we divided patients into tertil by Gensini score, we didn't find any relationship between groups.

A limitation of this study was the fact that most of the patients have low Gensini score.

\section{CONCLUSION}

There is no relationship between the existence and degree of coronary atherosclerosis and $\mathrm{PTH} / 25-\mathrm{OH}$ vitamin $\mathrm{D}$ levels in our cross-sectional study.

Other studies which consider chronic process of atherosclerosis are needed.

References

Smith JC, Page MD, John R, Wheeler MH, Cockroft JR, Scanlon MF, et al. Augmentation of central arterial pressure in mild primary hyperparathyroidism. J Clin Endocrinol Metab 2000; 85: 3515-3519.

Gensini $>20$ Gensini<20 p value

\begin{tabular}{|l|l|l|l|}
\hline $\begin{array}{l}\text { PTH } \\
\text { (pg/ml) }\end{array}$ & 49,39 & 52,14 & 0,51 \\
\hline D vit & 22,91 & 18,92 & 0,019 \\
\hline
\end{tabular}

(ng/ml)

Calcium

$(\mathrm{mg} / \mathrm{dl})$
9,72

9,56

0,003
Neunteufl T, Katzenschlager R, Abela C, Kostner K, Niederle B, Weidinger F, et al. Impairment of endothelium-independent vasodilatation in patients with hypercalcemia. Cardivasc Res 1998; 40:396-401

Piovesan A, Molineri N, Casasso F, Emmolo I, Ugliengo G, Cesario F, Left ventricular hypertrophy in primary hyperparathyroidism. Effects of successful parathyroidectomy. Clin endocrinol 1999; 50:321-328

Stefenelli T, Mayr h, Bergler-Klein J, Globits S, Woloszczczuk W, Niederle B. Primary hyperparathyroidism: incidence of cardiac abnormalities and partial reversibility after successful parathyroidectomy Am J Med 1993; 95: 197-202 